\title{
AVALIAÇÃO DO RISCO AMBIENTAL UTILIZANDO FMEA EM UMM LATICÍNIO NA REGIÃO DE LAVRAS - MG
}

\section{ENVIRONMENTAL RISK EVALUATION USING FMEA IN A DAIRY PLANT IN THE REGION OF LAVRAS - MG}

\author{
Amanda Cássia Nogueira* amandinha jcp@yahoo.com.br \\ Alexandre de Paula Peres* peres@dca.ufla.br \\ Ellen Moraes Carvalho* ellencarvalho@hotmail.com \\ *Universidade Federal de Lavras (UFLA)
}

\begin{abstract}
Resumo: Uma metodologia que vem sendo paulatinamente empregada na avaliação do risco ambiental durante o processo produtivo é o FMEA (do inglês - Failure Mode and Effect Analysis), definida como uma ferramenta que busca em princípio, evitar ou minimizar as chances do produto ou processo falhar, aumentando assim a sua confiabilidade. Considerando que o impacto ambiental gerado por um laticínio apresenta diversos riscos em potencial, este método foi empregado na avaliação do risco ambiental durante o processamento de queijos em um laticínio da região de Lavras - MG. Um levantamento das entradas e saídas de cada operação do processo foi feito e as saídas que apresentaram risco ambiental foram analisadas utilizando-se um formulário para aplicação do método. Ações foram sugeridas de acordo com as mesmas, colaborando para a diminuição da probabilidade do risco ambiental gerado ocorrer à medida que estas ações foram sendo aplicadas, contribuindo para um processo mais sustentável e eficiente.
\end{abstract}

Palavras-chave: FMEA. Gestão ambiental. Laticínio. Risco ambiental. Estudo de caso.

Abstract: A methodology has been gradually used in environmental risk assessment during the production process is the FMEA (Failure Mode and Effect Analysis), defined as a search tool that in principle, prevent or minimize the chances of the product or process fails, thereby increasing its reliability. Whereas the environmental impact generated by a plant has several potential risks, this method was employed to assess the environmental risk during the processing of cheese at a dairy in the region of Lavras - MG. A survey of inputs and outputs of each operation of the process was done and the outputs that showed environmental impacts were analyzed using a form for application of the method. Actions have been suggested according to them, helping to decrease the probability of environmental risk generated occur as these actions have been implemented, contributing to a more sustainable and efficient.

Keywords: FMEA. Environmental management. Dairy plant. Environmental risk. Study of case. 


\section{INTRODUÇÃO}

As empresas brasileiras de pequeno porte, as quais representam $98 \%$ das empresas (SEBRAE, 2010), de forma geral, têm enfrentado diversos problemas que afetam a sua sobrevivência como: crédito difícil, juros elevados e competição predatória interna e externa. Diante desse cenário, é natural que os pequenos empresários sintam-se distantes das questões ambientais, tratando-as, muitas vezes, como um compromisso secundário e de custo elevado, motivado, em grande parte, pela pressão dos órgãos de controle.

Contudo, o interesse crescente pela preservação do meio ambiente leva a um movimento progressista de conscientização da população no sentido de, cada vez mais, se consumir produtos e serviços que gerem menor impacto ambiental, exigindo uma adequação por parte das empresas (MACHADO, SILVA; FREIRE, 2001; MENDES, 2009).

Um fator relevante para as pequenas empresas se adequarem ambientalmente é o fortalecimento da legislação ambiental brasileira. As empresas que estiverem constantemente avaliando os seus processos em relação aos riscos ambientais, certamente estarão evitando problemas com os órgãos fiscalizadores (ZAMBRANO; MARTINS, 2007).

Dentre os vários benefícios trazidos para o processo pela melhoria na relação com o meio ambiente, Ferreira apud Porter (2007) destaca: economia de materiais, decorrentes do processamento, da substituição, da reutilização ou da reciclagem dos insumos de produção; melhor utilização dos subprodutos; menor consumo de energia; aumento do rendimento do processo; redução dos custos de armazenamento e manuseio de materiais; conversão de desperdícios na forma de valor; e eliminação ou redução do custo das atividades envolvidas na descarga, manuseio, transporte e descarte de resíduos.

A crescente necessidade de melhorar a qualidade de produtos e a satisfação dos clientes tem popularizado vários métodos e técnicas que visam melhorar a confiabilidade de produtos e processos, ou seja, aumentar a probabilidade de um item desempenhar sua função sem falhas. 
Embora, cada vez mais, a certificação ambiental se torne essencial para o fortalecimento da imagem da empresa e para sua permanência no mercado, ela ainda é bastante onerosa para as empresas, principalmente para as de pequeno porte.

Diante deste quadro, a utilização do método FMEA (do inglês - Failure Mode e Effect Analysis) para a avaliação do risco ambiental gerado pelas empresas pode ser vista como uma referência para os pequenos empresários começarem a diagnosticar o risco ambiental de seus processos produtivos, por meio da identificação de falhas, estabelecimento de prioridades para o tratamento das falhas e implantação de ações, com posterior análise das ações recomendadas para notificar a diminuição da probabilidade de ocorrência da falha (ZAMBRANO \& MARTINS, 2007). Além disso, a implantação de programas ambientais pode auxiliar as empresas a diminuírem seus custos devido ao aumento da eficiência.

$\mathrm{Na}$ tentativa de busca por soluções, as empresas de pequeno e médio porte vêm realizando parcerias com instituições de pesquisa e desenvolvimento com o intuito de suprir suas deficiências tecnológicas. Isso porque essas empresas não investem em tecnologias, devido aos altos custos com pesquisa e desenvolvimento (MENDES, 2009).

\section{LATICÍNIOS E SEUS RESÍDUOS}

O setor laticinista, que tem papel de destaque na economia mineira, se enquadra no setor de empresas de pequeno porte. Segundo Junqueira \& Zoccal (2007), os laticínios mineiros de capacidade de processamento instalada menor que dez mil litros/dia representam $49 \%$, os laticínios com capacidade entre 10 a 50 mil litros representam $28 \%$ do total e as empresas com capacidade diária entre 50 a 200 mil litros representam 17\%. Enquanto, as grandes empresas, cuja capacidade de processamento diária é superior a 200 mil litros, representam apenas $6 \%$ do total dos estabelecimentos de leite e derivados.

Segundo Andrade et al. (2002), as empresas do gênero alimentício pertencem ao setor econômico semi-concentrado, ou seja, são empresas que produzem bens de consumo não duráveis, o qual é classificado como de elevado impacto ambiental. 
Os principais impactos ambientais das indústrias de laticínios estão relacionados ao lançamento dos efluentes líquidos, à geração de resíduos sólidos e às emissões atmosféricas, geralmente sem nenhum tipo de controle e tratamento (MACHADO; SILVA; FREIRE, 2001).

Os efluentes líquidos das indústrias de laticínios abrangem os efluentes industriais (águas de lavagem de equipamentos e instalações), os esgotos sanitários gerados e as águas pluviais captadas na indústria (MACHADO, SILVA; FREIRE, 2001). Porém, o soro do leite, subproduto proveniente da fabricação de queijo, pode ainda se enquadrar nesse grupo, já que se torna muitas vezes descarte problemático, ao invés de ser fonte de renda para as empresas.

Os resíduos sólidos gerados nas pequenas e médias indústrias de laticínios incluem embalagens de papelão, lixo doméstico, cinzas de caldeiras, aparas de queijo e, em menor quantidade, metais e vidros. Como o volume desses resíduos é geralmente reduzido, soluções cômodas e simples de disposição final têm sido adotadas, sem utilização de critérios técnicos, podendo significar perdas econômicas e agressões ao meio ambiente.

As emissões atmosféricas na indústria de laticínios são provenientes da queima dos combustíveis nas caldeiras, geralmente a óleo ou à lenha, cujo vapor é utilizado para a limpeza e desinfecção de pisos e equipamentos e em etapas do processo produtivo (MACHADO, SILVA; FREIRE, 2001).

\section{OBJETIVO}

O objetivo deste trabalho, mediante a consideração de que o impacto ambiental gerado por laticínios apresenta diversos riscos em potencial, consistiu em utilizar o método FMEA para avaliar os riscos ambientais durante o processamento de leite para a produção de seus derivados em um laticínio da região de Lavras MG. 


\section{O Método FMEA}

Em 1963, aproximadamente, durante a missão Apollo, a agência norteamericana NASA (National Aeronautics and Space Administration) desenvolveu um método para identificar, de forma sistemática, falhas potenciais em sistemas, processos ou serviços, identificar seus efeitos, suas causas e, a partir disso, definir ações para reduzir ou eliminar o risco associado a essas falhas. Esse método foi chamado de Análise de Modos e Efeitos de Falha (FMEA) (PUENTE et al., 2002).

Mesmo tendo surgido em 1963, o FMEA somente passou a ser utilizado de forma mais abrangente após 1977, quando a Ford Motors Company começou a utilizar o método na fabricação de automóveis (GILCHRIST, 1993).

"É uma técnica sistematizada a qual identifica e classifica os modos potenciais de falha de um projeto ou processo de manufatura para priorizar ações de melhoria" (IQA, 2000). É uma ferramenta que busca, em princípio, evitar ou minimizar as chances do produto ou processo falhar, aumentando assim a sua confiabilidade.

O método FMEA avalia a severidade de cada falha relativamente ao impacto causado aos clientes, sua probabilidade de ocorrência e de detecção antes de chegarem às mãos dos clientes. Com base nos três elementos, severidade, ocorrência e detecção, o FMEA leva à priorização de quais modos de falha acarretam os maiores riscos ao cliente e que, portanto, merecem atenção (PUENTE et al., 2002).

Apesar de ter sido desenvolvida com um enfoque no projeto de novos produtos e processos, esta metodologia, pela sua grande utilidade, passou a ser aplicada de diversas maneiras. Aplicações da ferramenta FMEA, como apoio ao gerenciamento de processos, têm sido relatadas por pesquisadores de diversas áreas.

Destaca-se seu uso como suporte ao gerenciamento de riscos em serviços hospitalares (PAPARELLA, 2007; TRUCCO; CAVALLIN, 2006; REID, 2005; REILING; KNUTZEN; STOECKLEIN, 2003; SPATH, 2003).

Welborn (2007) relata sua aplicação à avaliação de riscos associados para estratégia de terceirização. Hsiao (2002) propõe uma integração da FMEA ao QFD 
(Quality Function Deployment), DFA (Design for Assembly) e AHP (Analytic Hierarchy Process) para uma análise das falhas no projeto de um brinquedo.

Price e Taylor (2002) relatam a aplicação do FMEA para estudo de falhas em sistemas complexos por meio da simulação. A aplicação na análise de falhas existentes em etapas de sistemas agroindustriais foi relatada recentemente por Bertolini; Bevilacqua; Massini (2006), Garrafa (2005), Garrafa; Rosa (2004) e Rosa; Garrafa (2009).

As principais etapas para execução do método FMEA são: definir o processo ou produto a ser analisado; definir a(s) função(es) do processo ou produto; identificar os possíveis modos de falha; identificar os possíveis efeitos de cada modo de falha para as pessoas que sofrem impacto do processo ou produto; estimar a severidade dessas falhas; identificar as causas raízes das possíveis falhas; estimar a probabilidade de ocorrência da falha; identificar o meio de detecção do modo de falha; estimar a probabilidade dessa falha ser detectada antecipadamente; determinar as prioridades; definir planos de ação para diminuir o risco (HELMAN; ANDERY, 1995).

Sua utilização na avaliação de risco ambiental também tem sido estudada e para seu melhor entendimento nesta área, faz-se necessário algumas definições.

$\mathrm{Na}$ ISO 14000, um aspecto ambiental é definido como um "elemento das atividades, produtos ou serviços de uma organização que possam interagir com o meio ambiente", enquanto impacto ambiental é "qualquer mudança no meio ambiente, adversa ou benéfica, que resulte, total ou parcialmente, das atividades, produtos ou serviços de uma organização". Já o risco ambiental pode ser definido como a probabilidade do impacto ambiental ocorrer.

Uma avaliação dos riscos/impactos ambientais é, portanto, o processo de se caracterizar os efeitos adversos potenciais da exposição a perigos/aspectos ambientais. Para a avaliação do risco de ocorrência de um impacto ambiental foi realizado um levantamento das entradas e saídas de cada operação do processo. As saídas que apresentaram risco ambiental foram analisadas. A tabela 1 apresenta o formulário utilizado para a aplicação do FMEA. 
Tabela 1 - Formulário do FMEA.



Fonte: Adaptado de Helman e Andery (1995).

De acordo com Zambrano e Martins (2007), as colunas deste formulário foram preenchidas da seguinte forma:

a) descrição das saídas - função: foram descritas as saídas e a sua função durante o processo produtivo;

b) tipo de impacto ambiental: os impactos ambientais que ocorrem cotidianamente na empresa estudada foram classificados como "real", por outro lado, os impactos que possam vir a ocorrer foram classificados como "potencial";

c) efeito do impacto ambiental: descrevem-se os meios envolvidos com o impacto ambiental, estes podem ser: a água, o solo e o ar;

d) causa do impacto ambiental: na maioria das vezes, a causa do impacto ambiental é o descarte incorreto dos resíduos e efluentes industriais;

e) controles atuais: são as atitudes que a empresa pesquisada adota para impedir que ocorra o impacto ambiental. Quando a empresa não adota nenhuma atitude para mitigar o impacto, esta coluna estará em branco;

f) as colunas "S", "O", "D", "A" e "R" representam a "severidade", a "ocorrência", a "detecção", a "abrangência do impacto" e o "risco ambiental";

g) controles ambientais - ações recomendadas: nesta coluna estão descritas as ações que as organizações deveriam adotar para mitigar os impactos ambientais. Quando os "controles atuais" da organização forem julgados 
como eficazes para mitigar os impactos ambientais, não será recomendada nenhuma ação.

Para realizar uma análise dos riscos ambientais, utilizando o FMEA, foi necessário adaptar os índices de severidade, ocorrência e detecção do impacto ambiental, além disso, foi acrescentado o índice de abrangência o impacto. Nas Tabelas 2, 3, 4 e 5 estão descritos os índices adotados. Adotou-se o índice de ocorrência igual 1 para os impactos ambientais potenciais.

Tabela 2 - Classificações de severidade.

\section{Severidade do impacto ambiental}

Classificação

\begin{tabular}{lll}
\hline Alta & Produtos muito danosos ao meio ambiente, & 3 \\
& que apresentam as características: \\
& corrosividade, reatividade, explosividade, \\
& toxicidade, inflamabilidade e patogenicidade & \\
\hline Moderada & Produtos danosos ao meio ambiente, que & 2 \\
& possuem longo tempo de decomposição, por \\
& exemplo: metais, vidros e plásticos. Também \\
& é considerada a utilização de recursos \\
& naturais \\
& Produtos pouco danosos ao meio ambiente, \\
& que possuem curto tempo de decomposição, \\
Baixa & como papelão e tecidos
\end{tabular}

O índice severidade considera as potenciais alterações que quaisquer produtos que não tenham sua alocação correta causam, tanto no âmbito de agressividade ao meio quanto no tempo de ação. 
Tabela 3 - Classificações de ocorrência de impactos ambientais reais.

\section{Ocorrência do impacto ambiental Classificação}

\begin{tabular}{lcc}
\hline Alta & O impacto ambiental ocorre diariamente & 3 \\
\hline Moderada & O impacto ambiental ocorre mensalmente & 2 \\
\hline Baixa & O impacto ambiental ocorre & 1 \\
& semestralmente ou anualmente & \\
\hline
\end{tabular}

Como demonstrado na Tabela 3, a periodicidade do impacto ambiental está inserido no índice ocorrência, indicando a possibilidade do acontecimento e conseqüentemente do gerenciamento que o mesmo requer.

Quanto à detecção do impacto (Tabela 4), considera-se a capacidade de percepção do mesmo. Quanto maior a percepção (deteç̧ão alta), menor a pontuação atribuída a este fator de risco.

Tabela 4 - Classificações de deteç̧ão.

Detecção do impacto ambiental Classificação

\begin{tabular}{lll}
\hline Baixa & $\begin{array}{l}\text { Para detectar o impacto ambiental é } \\
\text { necessária a utilização de tecnologias } \\
\text { sofisticadas }\end{array}$ & 3 \\
\hline Média & O impacto ambiental é percebido com a & 2 \\
& utilização de medidores simples. Exemplos: & \\
& hidrômetro e medidor de energia elétrica \\
\hline Alta & O impacto ambiental pode ser percebido & 1 \\
& visualmente
\end{tabular}


O índice de abrangência (Tabela 5) tem sua classificação de acordo com a localidade na qual o impacto pode ocorrer, quanto maior a área que envolve, maior a pontuação recebida.

Tabela 5 - Classificações de abrangência de impactos ambientais.

\begin{tabular}{lc}
\hline Abrangência do impacto ambiental & Classificação \\
\hline O impacto ambiental ocorre fora dos limites da & 3 \\
organização & 2 \\
\hline O impacto ambiental ocorre dentro dos limites da \\
organização \\
O impacto ambiental ocorre no local onde está sendo \\
realizada a operação
\end{tabular}

O índice risco ambiental (R), gerado da multiplicação dos índices "S", "O", "D" e "A", detecta a prioridade do risco, demonstrando as potenciais falhas. Quanto maior este índice, maior o impacto ambiental representado.

\section{ESTUDO DE CASO}

A empresa estudada se caracteriza pela preparação do leite e fabricação de produtos lácteos. Está localizada na zona rural da cidade de Lavras desde 1997 e possui 16 funcionários. Seus produtos são quatro tipos de queijo.

O estudo de levantamento de risco ambiental foi realizado de maneira única para todos os produtos, já que seus processos não diferem tanto a ponto de apresentarem diferenças significativas para cada tipo de queijo. As etapas de produção de queijo podem ser resumidas em: recepção, desnate (opcional), aquecimento e adição de ingredientes, agitação e corte, retirada do soro, compactação e corte, filagem (opcional), corte e preparo do produto final, salmoura, secagem e embalagem. 
Foi realizado um levantamento das entradas e saídas das etapas do processo de produção. As saídas que apresentaram risco ambiental são analisadas na matriz FMEA. A Tabela 6 ilustra o método. Pelo fato das saídas terem apresentado este índice elevado, discutiram-se os índices separadamente e em seguida as saídas relevantes.

Tabela 6 - FMEA

(continua)

\begin{tabular}{|c|c|c|c|c|c|c|c|c|c|c|}
\hline $\begin{array}{l}\text { Descrição } \\
\text { das saídas - } \\
\text { função }\end{array}$ & Tipo & $\begin{array}{l}\text { Efeito do } \\
\text { impacto } \\
\text { ambiental }\end{array}$ & $\begin{array}{c}\text { Causa do Impacto } \\
\text { Ambiental }\end{array}$ & $\begin{array}{l}\text { Controles } \\
\text { atuais }\end{array}$ & $\mathbf{S}$ & 0 & D & $\mathbf{A}$ & $\mathbf{R}$ & $\begin{array}{c}\text { Controles } \\
\text { ambientais - ações } \\
\text { recomendadas }\end{array}$ \\
\hline $\begin{array}{c}\text { Consumo de } \\
\text { energia }\end{array}$ & $R$ & $\begin{array}{l}\text { Utilização dos } \\
\text { recursos } \\
\text { naturais }\end{array}$ & $\begin{array}{c}\text { A energia elétrica } \\
\text { é utilizada na } \\
\text { operação dos } \\
\text { equipamentos }\end{array}$ & - & 2 & 3 & 2 & 3 & 36 & $\begin{array}{c}\text { Melhoria contínua } \\
\text { na minimização } \\
\text { do consumo e na } \\
\text { compra de novos } \\
\text { equipamentos, } \\
\text { preferir os que } \\
\text { consomem menos } \\
\text { energia elétrica }\end{array}$ \\
\hline $\begin{array}{l}\text { Consumo de } \\
\text { água }\end{array}$ & $\mathrm{R}$ & $\begin{array}{l}\text { Utilização dos } \\
\text { recursos } \\
\text { naturais }\end{array}$ & $\begin{array}{c}\text { A água é utilizada } \\
\text { no processo }\end{array}$ & - & 2 & 3 & 2 & 2 & 24 & $\begin{array}{c}\text { Contabilização do } \\
\text { consumo } \\
\text { Melhoria contínua } \\
\text { dos processos } \\
\text { para minimizar o } \\
\text { consumo de água } \\
\\
\text { Análise semestral } \\
\text { para sua } \\
\text { utilização na } \\
\text { caldeira }\end{array}$ \\
\hline $\begin{array}{c}\text { Consumo e } \\
\text { armazename } \\
\text { nto da lenha }\end{array}$ & $R$ & $\begin{array}{l}\text { Utilização dos } \\
\text { recursos } \\
\text { naturais }\end{array}$ & $\begin{array}{c}\text { A lenha é utilizada } \\
\text { para alimentar a } \\
\text { caldeira }\end{array}$ & $\begin{array}{c}\text { A lenha } \\
\text { utilizada é } \\
\text { legalizada }\end{array}$ & 2 & 3 & 1 & 3 & 18 & $\begin{array}{l}\text { Construção de um } \\
\text { local para } \\
\text { armazenamento } \\
\text { de lenha (pelo } \\
\text { menos uma } \\
\text { cobertura) } \\
\text { Busca de } \\
\text { informações mais } \\
\text { precisas sobre a } \\
\text { lenha de café } \\
\text { (também utilizada) } \\
\text { em virtude do seu } \\
\text { menor preço }\end{array}$ \\
\hline $\begin{array}{c}\text { Embalagens } \\
\text { de matérias } \\
\text {-primas, } \\
\text { insumos, } \\
\text { embalagens } \\
\text { de papel e } \\
\text { plástico }\end{array}$ & $R$ & $\begin{array}{l}\text { Contaminação } \\
\text { do solo }\end{array}$ & $\begin{array}{c}\text { As embalagens } \\
\text { são } \\
\text { encaminhadas a } \\
\text { empresa de coleta } \\
\text { de lixo }\end{array}$ & $\begin{array}{c}\text { As } \\
\text { embalagen } \\
\text { s são } \\
\text { separadas } \\
\text { de acordo } \\
\text { com seus } \\
\text { respectivos } \\
\text { materiais }\end{array}$ & 2 & 3 & 1 & 3 & 18 & $\begin{array}{c}\text { As embalagens já } \\
\text { separadas devem } \\
\text { ser encaminhadas } \\
\text { para reciclagem }\end{array}$ \\
\hline
\end{tabular}

Revista Produção Online, v.11, n.1, p. 194-209, mar., 2011 
Tabela 6 - FMEA

(conclusão)

\begin{tabular}{|c|c|c|c|c|c|c|c|c|c|}
\hline $\begin{array}{l}\text { Embalagens } \\
\text { com } \\
\text { resíduos } \\
\text { orgânicos }\end{array}$ & $\mathrm{R}$ & $\begin{array}{l}\text { Contaminação } \\
\text { do solo }\end{array}$ & $\begin{array}{c}\text { As embalagens } \\
\text { são } \\
\text { encaminhadas a } \\
\text { empresa de coleta } \\
\text { de lixo }\end{array}$ & - & 23 & 1 & 3 & 18 & $\begin{array}{l}\text { Minimização da } \\
\text { geração dessas } \\
\text { embalagens } \\
\text { Devem ser } \\
\text { lavadas e então } \\
\text { destinadas à } \\
\text { reciclagem }\end{array}$ \\
\hline $\begin{array}{l}\text { Sujeira do } \\
\text { chão de } \\
\text { fábrica }\end{array}$ & $\mathrm{R}$ & $\begin{array}{l}\text { Contaminação } \\
\text { do solo e/ou } \\
\text { da água }\end{array}$ & $\begin{array}{l}\text { Parte da sujeira é } \\
\text { encaminhada } \\
\text { para a empresa } \\
\text { de coleta de lixo e } \\
\text { outra descartada } \\
\text { em um curso } \\
\text { d'água junto com } \\
\text { a água residual do } \\
\text { processamento }\end{array}$ & - & 23 & 1 & 3 & 18 & $\begin{array}{l}\text { Destinada à } \\
\text { reciclagem e } \\
\text { reaproveitamento } \\
\text { do lixo orgânico } \\
\text { para adubo }\end{array}$ \\
\hline $\begin{array}{c}\text { Água } \\
\text { proveniente } \\
\text { da } \\
\text { higienização } \\
\text { de pisos e } \\
\text { equipamento } \\
\text { s }\end{array}$ & $\mathrm{R}$ & $\begin{array}{l}\text { Contaminação } \\
\text { da água }\end{array}$ & $\begin{array}{l}\text { Descartada em } \\
\text { um curso d'água } \\
\text { próximo a } \\
\text { empresa }\end{array}$ & - & 23 & 2 & 3 & 36 & $\begin{array}{c}\text { Destinada à } \\
\text { estação de } \\
\text { tratamento de } \\
\text { efluentes, a qual } \\
\text { deve ser } \\
\text { construída }\end{array}$ \\
\hline Salmoura & $\mathrm{R}$ & $\begin{array}{l}\text { Contaminação } \\
\text { do solo e/ou } \\
\text { da água }\end{array}$ & - & - & 22 & 2 & 3 & 24 & - \\
\hline Soro & $\mathrm{R}$ & $\begin{array}{l}\text { Contaminação } \\
\text { do solo e/ou } \\
\text { da água }\end{array}$ & $\begin{array}{l}\text { O soro é um } \\
\text { resíduo do } \\
\text { processamento }\end{array}$ & $\begin{array}{l}\text { Destinado } \\
\text { à } \\
\text { alimentaçã } \\
\text { o suína }\end{array}$ & 23 & 1 & 3 & 18 & $\begin{array}{l}\text { Adequação do } \\
\text { tanque de } \\
\text { armazenamento } \\
\text { (fechamento e } \\
\text { capacidade) }\end{array}$ \\
\hline $\begin{array}{c}\text { Fumaça da } \\
\text { caldeira }\end{array}$ & $\mathrm{P}$ & $\begin{array}{l}\text { Contaminação } \\
\text { do ar }\end{array}$ & - & - & 23 & 2 & 2 & 24 & $\begin{array}{l}\text { Instalação de um } \\
\text { filtro }\end{array}$ \\
\hline Cinzas & $\mathrm{R}$ & $\begin{array}{l}\text { Contaminação } \\
\text { da água }\end{array}$ & $\begin{array}{l}\text { Proveniente da } \\
\text { queima da lenha } \\
\text { na caldeira }\end{array}$ & - & 23 & 2 & 2 & 24 & $\begin{array}{l}\text { Aplicação em } \\
\text { solos de cultivo }\end{array}$ \\
\hline
\end{tabular}

Quanto à severidade, todas as entradas apresentaram índice moderado, caracterizado pela utilização de recursos naturais e de produtos danosos que possuem longo período de decomposição (plásticos, papéis, embalagens com resíduos orgânicos). Já nas saídas, a ocorrência esteve entre alta e moderada, detectando impactos diários e mensais e demonstrando a necessidade de gerenciamento. 
A detecção dos impactos geralmente pode ser realizada visualmente, ou então, utilizando métodos simples, o que facilita o controle. Já a abrangência ocorre fora dos limites da empresa, fator preocupante.

O fato da empresa ainda não ter uma estação de tratamento de efluentes é um risco proeminente, já que todos os efluentes líquidos são destinados a um curso d'água próximo ao laticínio. A recomendação de construí-la foi acatada, visto que já era um projeto da empresa, o qual foi impulsionado pelo método diante da prioridade que representava.

O consumo e armazenamento de lenha também foi uma saída que causou risco. A não manutenção periódica da caldeira acarretava gasto elevado de lenha, o que era agravado pelo seu não armazenamento. A limpeza realizada na caldeira diminuiu o gasto de lenha à metade e será feita a construção de uma cobertura para que a mesma seja armazenada, o que diminuirá a despesa com este combustível, já que a lenha apresentará menor teor de umidade.

O soro também se apresentou como um risco devido ao seu armazenamento deficiente. Todo o soro proveniente do processo era destinado a um tanque do qual era bombeado para alimentação animal. Porém, este tanque permanecia aberto e, muitas vezes, transbordava em virtude de uma maior produção, sendo enviado para o curso d'água. A recomendação inicial foi o fechamento adequado deste tanque e a construção futura de um novo tanque com dimensões corretas.

As cinzas, que até então não tinham destino e se caracterizam como risco ambiental, estão sendo usadas para aplicação em solos de cultivo. Da mesma forma, a coleta seletiva está sendo feita. Uma escola da região tem recebido alguns papéis e plásticos, anteriormente descartados, para utilizá-los em artesanatos.

Zambrano; Martins (2007) utilizando este método para avaliação do risco ambiental em uma empresa do setor alimentício, caracterizada pela fabricação de suco de laranja e óleos essenciais, encontraram como risco ambiental significativo o descarte do óleo lubrificante da embalagem no solo, o qual deve ser encaminhado para o refino em uma empresa cadastrada na Agência Nacional de Petróleo.

Por outro lado, o bagaço da laranja, assim como o lodo de tratamento de efluentes teve seus destinos adequados: produção de pectina e adubo, respectivamente, não implicando em riscos ambientais significativos. 


\section{CONSIDERAÇÕES FINAIS}

Diante dos riscos ambientais que os laticínios causam e do custo oneroso que representa a certificação ambiental, principalmente para as pequenas empresas, das quais os laticínios fazem parte em sua maioria, o método FMEA se torna uma referência para o diagnóstico do risco ambiental gerado pelos mesmos. Além de ter a vantagem de fácil utilização, de possibilitar a constante avaliação do risco ambiental e a adoção de ações que conduzirão a organização na melhoria contínua de seus processos.

A utilização do FMEA avaliou esses riscos e propôs ações no processamento de queijos em um laticínio da região de Lavras, demonstrando a mudança de percepção quanto à questão ambiental.

A não preocupação quanto à utilização, diminuição ou mesmo medição do consumo de recursos renováveis, anteriormente verificada, transformou-se em vigilância e conscientização de valores que podem se juntar ao lucro da empresa.

As ações que foram adotadas já demonstraram diminuição no impacto ambiental. As demais já estão sendo postas em prática, em virtude de a empresa ter-se conscientizado da importância que o gerenciamento ambiental representa e da contribuição do mesmo para a adequação à legislação, para o fortalecimento da sua imagem e para sua permanência no mercado.

Por focar pequenas empresas, o método tem o objetivo de despertar nelas a preocupação ambiental. Diante do fato de representarem a maioria das empresas brasileiras, os impactos gerados pelas mesmas, quando coletivamente, tornam-se significativos, demonstrando a importância dessa conscientização. Consciência esta, notada ao fim do trabalho, não só diante da necessidade de questões legais e econômicas, mas de ordem de bem estar da população e de preservação de recursos naturais.

Nota

Texto inédito, resultado do Programa de Bolsa de Extensão da Universidade Federal de Lavras. 


\section{REFERÊNCIAS}

ANDRADE, R. O. B.; TACHIZAWA, T.; CARVALHO, A. B. Gestão ambiental: enfoque estratégico aplicado ao desenvolvimento sustentável. 2 ed. São Paulo: Makron Books, 2002. 232 p.

BERTOLINI, M.; BEVILACQUA, M.; MASSINI, R. FMECA approach to product traceability in the food industry. Food Control, v. 17, n. 2, p. 137-145, 2006.

FERREIRA, J. C.; FRANCISCO, A. C. Gestão Ambiental fator competitivo dentro do mundo dos negócios. Ponta Grossa, 2007.

GARRAFA, M. Aplicação de FMEA na otimização dos fatores de produção da canola. Santa Maria, 2005. 166 p. Dissertação (Mestrado em Engenharia de Produção) - Universidade Federal de Santa Maria, Santa Maria, RS.

GARRAFA, M.; ROSA, L. C. Priorização de ações em cultivo de canola (Brassica napus L.var.oleifera) na Escola-Fazenda da SETREM - subprocesso semeadura. ENCONTRO NACIONAL DE ENGENHARIA DE PRODUÇÃO, 24., 2004, Florianópolis. Anais... Rio de Janeiro: ABEPRO, 2004. CD-ROM.

GILCHRIST, W. Modeling failure modes and effects analysis. International Journal of Quality \& Reliability Management, Bradford, v. 10, n. 5, p. 16-24, 1993.

JUNQUEIRA, R. V. B.; ZOCCAL, R. A Indústria de laticínio no Estado de Minas Gerais - Panorama do leite on line, Embrapa, Ano 2, n 13, 2007. Disponível em: < http://www.cnpgl.embrapa.br/panorama/produtos13.html> Acesso em: fev. 2010.

HELMAN, H.; ANDERY, P. R. P. Análise de falhas (aplicação dos métodos de FMEA e FTA). Belo Horizonte: Fundação Christiano Ottoni, 1995. 174 p.

HSIAO, S. W. Concurrent design method for developing a new product. International Journal of Industrial Ergonomics, v. 29, n. 1, p. 41-55, 2002.

INSTITUTO DA QUALIDADE AUTOMOTIVA (IQA). Processo de Aprovação de Peça de Produção (PPAP). 3. ed. Brasil, 2000. 103 p.

MACHADO, R. M. G.; SILVA, P. C.; FREIRE, V. H. Controle ambiental em laticínios. Brasil Alimentos, n. 7, 2001.

MENDES, L. Gestão ambiental, custo ou benefício para a micro e pequena empresa?: Um estudo de caso no setor de laticínios. VI SEMEAD. Disponível em: $<$ www.ead.fea.usp.br/.../019Adm-

20Gestao\%20Ambiental,\%20Custo\%20ou\%20Benef\%ED cio.doc> Acesso em: dez. 2009. 
PAPARELLA, S. Failure mode and effects analysis: a useful tool for risk identification and injury prevention. Journal of Emergency Nursing, v. 33, n. 4, p. 367-371, 2007.

PRICE, C. J.; TAYLOR, N. S. Automated multiple failure FMEA. Reliability Engineering and System Safety, v. 76, n. 1, p. 1-10, 2002.

PUENTE, J.; PINO, R.; PRIORE, P.; FOUENTE, D de L. A decision support system for applying failure mode and effects analysis. International Journal of Quality \& Reliability Management, Bradford, v. 19, n. 2, p. 137-151, 2002.

REID, R. D. FMEA: something old, something new. Quality Progress, v. 38, n. 5, p. 90-93, 2005.

REILING, J. G.; KNUTZEN, B. L.; STOECKLEIN, M. FMEA: the cure for medical errors. Quality Progress, v. 36, n. 8, p. 67-71, 2003.

ROSA, L. C.; GARRAFA, M. Análise dos modos de falha e efeitos na otimização dos fatores de produção no cultivo agrícola: subprocesso colheita da canola. Gestão e Produção, São Carlos, v. 16, n. 1, 2009.

SERVIÇO BRASILEIRO DE APOIO ÀS MICRO E PEQUENAS EMPRESAS (SEBRAE). Conhecendo a MPE. Disponível em: <http://www.sebraesp.com.br>. Acesso em: nov. 2009.

SPATH, P. L. Using failure mode and effects analysis to improve patient safety. AORN Journal, v. 78, n. 1, p. 15-37, 2003.

TRUCCO, P.; CAVALLIN, M. A quantitative approach to clinical risk assessment: the CREA method. Safety Science, v. 44, n. 6, p. 491-513, 2006.

WELBORN, C. Using FMEA to assess outsourcing risk. Quality Progress, v. 40, n. 8, p. 17-21, 2007.

ZAMBRANO, T. F.; M. M. F. Utilização do Método FMEA para avaliação do risco ambiental. Gestão e Produção, São Carlos, v. 14, n. 2, p. 295-309, mai/ago. 2007.

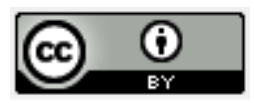

Artigo recebido em 04/02/2010 e aceito para publicação em 24/10/2010. 